\title{
Genomic analysis of cow mortality and milk production using a threshold-linear model
}

\author{
S. Tsuruta, ${ }^{* 1}$ D. A. L. Lourenco, ${ }^{*}$ I. Misztal, ${ }^{*}$ and T. J. Lawlor† \\ *Animal and Dairy Science Department, University of Georgia, Athens 30602 \\ †Holstein Association USA Inc., Brattleboro, VT 05301
}

\begin{abstract}
The objective of this study was to investigate the feasibility of genomic evaluation for cow mortality and milk production using a single-step methodology. Genomic relationships between cow mortality and milk production were also analyzed. Data included 883,887 (866,700) first-parity, 733,904 (711,211) second-parity, and $516,256(492,026)$ third-parity records on cow mortality (305-d milk yields) of Holsteins from Northeast states in the United States. The pedigree consisted of up to 1,690,481 animals including 34,481 bulls genotyped with 36,951 SNP markers. Analyses were conducted with a bivariate threshold-linear model for each parity separately. Genomic information was incorporated as a genomic relationship matrix in the single-step BLUP. Traditional and genomic estimated breeding values (GEBV) were obtained with Gibbs sampling using fixed variances, whereas reliabilities were calculated from variances of GEBV samples. Genomic EBV were then converted into single nucleotide polymorphism (SNP) marker effects. Those SNP effects were categorized according to values corresponding to 1 to 4 standard deviations. Moving averages and variances of SNP effects were calculated for windows of 30 adjacent SNP, and Manhattan plots were created for SNP variances with the same window size. Using Gibbs sampling, the reliability for genotyped bulls for cow mortality was 28 to $30 \%$ in EBV and 70 to $72 \%$ in GEBV. The reliability for genotyped bulls for 305-d milk yields was 53 to $65 \%$ to 81 to $85 \%$ in GEBV. Correlations of SNP effects between mortality and 305-d milk yields within categories were the highest with the largest SNP effects and reached $>0.7$ at 4 standard deviations. All SNP regions explained less than $0.6 \%$ of the genetic variance for both traits, except regions close to the DGAT1 gene, which explained up to $2.5 \%$ for cow mortality and $4 \%$ for 305-d milk yields. Reliability for GEBV
\end{abstract}

Received January 30, 2017.

Accepted May 6, 2017.

${ }^{1}$ Corresponding author: shogo@uga.edu with a moderate number of genotyped animals can be calculated by Gibbs samples. Genomic information can greatly increase the reliability of predictions not only for milk but also for mortality. The existence of a common region on Bos taurus autosome 14 affecting both traits may indicate a major gene with a pleiotropic effect on milk and mortality.

Key words: cow mortality, estimated breeding value reliability, genomic data, US Holstein

\section{INTRODUCTION}

According to the USDA-APHIS (2008), the cow mortality rate increased from $3.8 \%$ in 1996 to $5.7 \%$ in 2007. The top cause of death was lameness or injury (20.0\%) followed by mastitis (16.5\%) and calving problems (15.2\%). McConnel et al. (2008) reported that cow mortality was associated with lameness, respiratory disease, and mastitis. Involuntary culling affects animal welfare and profitability of dairy producers (Rushen and de Passillé, 2013). De Vries (2013) advocated that declining cow mortality is profitable for dairy producers. Tokuhisa et al. (2014) looked at cow mortality based on one of the DHI termination codes. The fraction of the code "dead" increased between 1998 and 2007 from $1.1 \%$ to $4.0 \%$, from $1.4 \%$ to $6.1 \%$, and from $1.8 \%$ to $9.4 \%$ for first, second, and third parities, respectively. Some of the increases could be due to changes in definition of termination codes. Cow mortality, which includes voluntary culling and involuntary culling, is a part of the traits in productive life for genetic evaluation (Miller et al., 2008). Voluntary culling has a salvage value, whereas involuntary culling has a disposal cost. Therefore, culled cow values between voluntary culling and involuntary culling could be significantly different. Tokuhisa et al. (2014) analyzed the relationship between mortality and milk yields in 3 parities with a threshold-linear model in 3 US regions. Mortality peaked in the summer months and increased with parity. Heritability estimates for mortality varied between regions and parities and ranged from 4 to $7 \%$. Genetic correlations between mortality and milk yields 
were positive but low, ranging from 0.0 to 0.3 . These results suggest that genetic selection for both mortality and milk production can create a healthy cow with a long productive life.

Wright and VanRaden (2016) looked at the possibility of routine genetic evaluations for livability, and the Council on Dairy Cattle Breeding has started cow livability evaluations (Council on Dairy Cattle Breeding, 2016a). Heritability on the observed scale was $1.3 \%$, and reliabilities for young bulls were $30 \%$ for parent average and $56 \%$ for genomic predictions. The correlation of predictions between livability and productive life was 0.70 , indicating that selection for productive life also selects against mortality, but selection for mortality as a separate trait will add more weight on involuntary culling. In a refined analysis, VanRaden (2016) found that heritability of livability computed only $0.6 \%$ with a sire model on the observed scale.

Milk yields and mortality are not simple traits because milk contains several proteins and fats, lactose, minerals, and water and causes of cows' deaths can vary. One or several genes can affect each milk content and each reason of death. Positive correlations between milk yields and mortality as found by Tokuhisa et al. (2014) and Tsuruta et al. (2014) suggest pleiotropy or another trait that could affect both traits, such as body size or BW. In dairy, quantitative traits such as milk production are associated with polygenes having small additive effects (Cole et al., 2009). There is a question of how many SNP for milk and mortality share significantly large effects.

Heritability of categorical traits such as mortality and conception rate on the observed scale is a function of incidence rate but is independent of the incidence rate on the underlying scale in a threshold model (Gianola and Foulley, 1983). If mortality in a herd not under the DHI recording system is higher, analyses with a threshold model may allow for better extrapolation of a genetic response due to selection in the herd. Although the threshold model was originally defined for sire models, higher accuracies of selection were found with animal models, especially in bivariate models where the correlated trait is linear (Ramirez-Valverde et al., 2001). Such a model is routinely used for calving ease and birth weight evaluation in beef cattle (Lourenco et al., 2015). A Markov chain Monte Carlo (MCMC) method via Gibbs sampling for threshold and linear models could be a useful tool to analyze bivariate traits because all of the theory in genetic evaluation holds in the underlying scale (Van Tassell et al., 1998; Varona et al., 1999). Tsuruta et al. (2015) successfully estimated (co)variance components for the DHI termination codes as binary traits and milk yields as a linear trait in US
Holsteins, using Gibbs sampling for a threshold-linear model.

The objectives of this study were to (1) conduct genomic evaluation for mortality and 305-d milk yields from the national DHI program using a threshold-linear model via Gibbs sampler; (2) estimate reliabilities for cows and bulls using prediction error variances (PEV) estimated from Gibbs samples; and (3) search for regions of the genome that are commonly associated with 305-d milk yields and mortality and could indicate potential pleiotropy.

\section{MATERIALS AND METHODS}

\section{Data}

Cow mortality and 305-d mature-equivalent milk yields from the DHI Program were obtained from USDA-ARS (Beltsville, MD). Cow mortality is one of the DHI termination codes reported as "dead." A data set from the US Northeast states (Maine, New Hampshire, Vermont, Massachusetts, Rhode Island, Connecticut, and New York) was used because a stronger genetic relationship between the 2 traits was found compared with other US regions (Southeast and Southwest states) in a previous study by Tsuruta et al. (2014). Table 1 shows means and standard deviations of 305-d milk yields and cow mortality for the first 3 parities. The data included 516,256 to 883,887 records $(2,134,047$ records in total) and 1,193,784 to $1,690,481$ animals in pedigree for the 3 parities for Holstein cows calving from 1999 to 2008. Genomic data for 34,506 bulls were also obtained from USDA-ARS and contained 42,503 SNP from the Illumina BovineSNP50 BeadChip (Illumina Inc., San Diego, CA). Using the following quality controls, 36,951 SNP markers for 34,481 bulls were kept for the analysis after cleaning up genotypes: (1) animals or SNP with call rate $<0.9,(2)$ SNP with minor allele frequency $<0.05$, (3) monomorphic SNP, and (4) parent-progeny Mendelian conflicts.

Table 1. Cow mortality (\%), means and SD of 305-d milk yield, and numbers of records and animals in pedigree for the first 3 parities

\begin{tabular}{lrrr}
\hline & \multicolumn{3}{c}{ Parity } \\
\cline { 2 - 4 } Trait & \multicolumn{1}{c}{1} & \multicolumn{1}{c}{3} \\
\hline Cow mortality & 2.2 & 3.7 & 5.4 \\
305-d milk & & & 10,696 \\
Mean & 11,341 & 11,015 & 2,099 \\
SD & 2,065 & 2,160 & 516,256 \\
No. of records & & & 492,026 \\
Cow mortality & 883,887 & 733,904 & $1,193,784$ \\
305-d milk & 866,700 & 711,211 & \\
No. of animals & $1,690,481$ & $1,489,523$ &
\end{tabular}


Table 2. Herd-year [V(hy)], additive genetic [V(a)] and residual $[\mathrm{V}(\mathrm{e})]$ variances, genetic and residual correlations, and heritability for cow mortality and 305-d milk yield $\left(\times 1,000 \mathrm{~kg}^{2}\right)$ used to predict EBV and genomic EBV for the first 3 parities (Tsuruta et al., 2014)

\begin{tabular}{|c|c|c|c|}
\hline \multirow[b]{2}{*}{ Parameter } & \multicolumn{3}{|c|}{ Parity } \\
\hline & 1 & 2 & 3 \\
\hline \multicolumn{4}{|l|}{ Cow mortality } \\
\hline V(hy) & 0.150 & 0.158 & 0.156 \\
\hline$V(a)$ & 0.066 & 0.056 & 0.048 \\
\hline $\mathrm{V}(\mathrm{e})$ & 1.0 & 1.0 & 1.0 \\
\hline Heritability & 0.03 & 0.03 & 0.04 \\
\hline \multicolumn{4}{|l|}{$305-d$ milk yield ${ }^{1}$} \\
\hline $\mathrm{V}(\mathrm{a})$ & 0.872 & 0.637 & 0.480 \\
\hline $\mathrm{V}(\mathrm{e})$ & 1.599 & 1.992 & 2.059 \\
\hline Heritability & 0.353 & 0.242 & 0.189 \\
\hline Genetic correlation & 0.28 & 0.34 & 0.19 \\
\hline Residual correlation & 0.02 & 0.09 & 0.11 \\
\hline
\end{tabular}

${ }^{1}$ Variances for 305 -d milk yield multiplied by $1,000^{2}$.

\section{Model}

Analyses used a bivariate threshold-linear animal model with cow mortality as a binary trait modeled in the underlying scale as multivariate normal or probit and 305-d milk yields as a linear trait. The model included herd year (treated as random for cow mortality), age at calving, month of death and DIM class as fixed effects, and random additive genetic and residual effects. To see different gene effects in each parity, the same model was applied separately for each of the 3 parities. A repeatability model cannot be used to see if cow mortality is genetically different among parities. A multiple trait model may be a better choice to see genetic differences among parities, but it was difficult to reach convergence (as conducted in a preliminary analysis) and would not be practical for a large data set. Parameters used in the model were fixed to (co) variance components estimated by Tsuruta et al. (2014) as shown in Table 2.

\section{Computations}

Computations were done using the THRGIBBS1F90 program (version 2.107) via Gibbs sampler (Tsuruta and Misztal, 2006) updated for genomic analyses using a single-step methodology (Aguilar et al., 2010), as documented in Misztal et al. (2016). Breeding values for both traits were estimated for each parity separately with and without the genomic information. Each analysis consisted of 5,500 samples, with the first 500 samples discarded as burn-in. Posterior means and standard deviations for GEBV and EBV were calculated based on 5,000 samples. With Gibbs sampling, the square of the posterior standard deviation is the
Table 3. Pairwise correlations of EBV and genomic EBV (GEBV) among 3 parities for cow mortality and 305-d milk yield using all animals

\begin{tabular}{lccccc}
\hline & \multicolumn{2}{c}{ Cow mortality } & & \multicolumn{2}{c}{ 305-d milk yield } \\
\cline { 2 - 3 } \cline { 5 - 6 } Parity & EBV & GEBV & & EBV & GEBV \\
\hline $1: 2$ & 0.83 & 0.83 & & 0.68 & 0.69 \\
$2: 3$ & 0.81 & 0.81 & & 0.74 & 0.75 \\
$1: 3$ & 0.76 & 0.75 & & 0.62 & 0.63 \\
\hline
\end{tabular}

$\mathrm{PEV}$, which can be directly calculated by inverting the left-hand side of the mixed model equations (MME; Jamrozik et al., 2000; Sorensen and Gianola, 2002). Individual reliability for EBV and GEBV is defined as $1-\mathrm{PEV} /\left[\mathrm{V}(\mathrm{a}) \operatorname{diag}\{\mathbf{G}\}_{\mathrm{i}}\right]$, where $\mathrm{V}(\mathrm{a})$ is the additive genetic variance and $\operatorname{diag}\{\mathbf{G}\}_{\mathrm{i}}$ is the diagonal of the genomic relationship matrix $(\mathbf{G})$ for genotyped animal $\mathrm{i}$ or the numerator relationship matrix $(\mathbf{A})$ for nongenotyped animal i (Van Vleck, 1993). Both A and G included inbreeding coefficients $(\mathrm{F})$ in this study. Therefore, $\operatorname{diag}\{\mathbf{G}\}_{\mathrm{i}}=1+\mathrm{F}_{\mathrm{i}}$ for animal i. The average inbreeding was $3.5 \%$, and the diagonals ranged from 0.83 to 1.41 and from 1.0 to 1.44 for $\mathbf{G}$ and $\mathbf{A}$, respectively. Diagonals and off-diagonals of $\mathbf{G}$ were rescaled to those for genotyped animals in A. The average reliability was calculated for EBV and GEBV for all genotyped animals. For genomic-wide association study, mean GEBV were converted to SNP marker effects by the POSTGSF90 program (Aguilar et al., 2014), following the methodology of Wang et al. (2012). The total genetic variance can be calculated as the sum of additive genetic variances for all SNP effects: $2 p_{\mathrm{i}}\left(1-p_{\mathrm{i}}\right) \widehat{a_{\mathrm{i}}^{2}}$, where $p_{\mathrm{i}}$ is the allele frequency at ith SNP and $\widehat{a_{\mathrm{i}}}$ is the estimated substitution effect of the ith SNP, assuming that all SNP are independent (Zhang et al., 2010). Manhattan plots were constructed with variances of 30 adjacent SNP marker effects (approximately equivalent to $1 \mathrm{Mbp}$ ). The total variance of these SNP variances underestimates the additive genetic variance because SNP effects are regressed toward the mean. The SNP variance at each SNP location was

Table 4. Pairwise correlations of EBV and genomic EBV (GEBV) among 3 parities for cow mortality and 305-d milk yield using only genotyped bulls

\begin{tabular}{lccccc}
\hline & \multicolumn{2}{c}{ Cow mortality } & & \multicolumn{2}{c}{$305-\mathrm{d}$ milk yield } \\
\cline { 2 - 3 } \cline { 5 - 6 } Parity & EBV & GEBV & & EBV & GEBV \\
\hline $1: 2$ & 0.74 & 0.91 & & 0.74 & 0.83 \\
$2: 3$ & 0.70 & 0.90 & & 0.79 & 0.89 \\
$1: 3$ & 0.63 & 0.84 & & 0.66 & 0.76 \\
\hline
\end{tabular}


Table 5. Reliability in EBV and genomic EBV (GEBV) for cow mortality and 305-d milk yield in the first 3 parities for common genotyped bulls (for all 34,481 genotyped bulls in parentheses)

\begin{tabular}{|c|c|c|c|c|c|c|c|}
\hline \multirow[b]{3}{*}{ Parity } & \multirow{3}{*}{$\begin{array}{l}\text { No. of } \\
\text { genotyped } \\
\text { bulls }\end{array}$} & \multicolumn{4}{|c|}{ Cow mortality } & \multirow{2}{*}{\multicolumn{2}{|c|}{$\frac{\text { 305-d milk yield }}{\text { Linear model }}$}} \\
\hline & & \multicolumn{2}{|c|}{ Threshold model } & \multicolumn{2}{|c|}{ Linear model } & & \\
\hline & & $\mathrm{EBV}$ & GEBV & EBV & GEBV & $\mathrm{EBV}$ & GEBV \\
\hline 1 & 5,024 & 0.30 & $0.72(0.73)$ & 0.50 & $0.80(0.77)$ & 0.65 & $0.85(0.79)$ \\
\hline 2 & 4,528 & 0.29 & $0.71(0.73)$ & 0.47 & $0.79(0.76)$ & 0.59 & $0.83(0.78)$ \\
\hline 3 & 3,956 & 0.28 & $0.70(0.72)$ & 0.43 & $0.77(0.75)$ & 0.53 & $0.81(0.77)$ \\
\hline
\end{tabular}

expressed as a percentage of the total genetic variance. Estimated SNP marker effects were categorized into 4 groups by their standard deviation to calculate correlations of SNP effects between cow mortality and 305-d milk yields within each category.

\section{RESULTS AND DISCUSSION}

\section{Correlations of EBV and GEBV Among Parities}

Pairwise correlations of EBV and GEBV among parities were calculated for cow mortality and for 305-d milk yields using all animals (Table 3 ) and only genotyped bulls (Table 4). The correlations of EBV and GEBV between parities 1 and 3 were the lowest but higher than 0.6 for both traits using all animals. The correlations for cow mortality were about 0.1 higher than those for milk production. Whereas the correlations of EBV and GEBV for cow mortality from only genotyped bulls were 0.1 lower and 0.1 higher than those from all animals, respectively, all correlations for milk production from genotyped bulls were higher than those for all animals. These results suggest that cow mortality and milk production in 3 parities can be treated as different traits except for cow mortality with $>0.85$ correlations for genotyped bulls.

\section{Means and Distributions of Reliabilities}

The reliability calculated with PEV by inverting the left-hand side of MME is potentially unaffected by selection but is dependent on genetic parameters. However, the direct inversion of a large number of MME is not feasible in practice. The MCMC via Gibbs sampling for threshold and linear models may be useful for a large data set to estimate PEV, assuming that genetic parameters are known. Table 5 shows average reliabilities of EBV and GEBV obtained without and with genomic information, respectively, for genotyped bulls in each parity separately. Numbers of genotyped bulls in Table 5 indicate the number of common genotyped bulls used in both EBV and GEBV (i.e., only genotyped bulls with daughters were included in both EBV and GEBV). On the other hand, reliabilities of GEBV in parentheses are for all 34,481 genotyped bulls with and without daughters. For cow mortality, the reliabilities in EBV were 28 to $30 \%$ without the genomic information, rising to 70 to $72 \%$ for GEBV when genomic information was used. For milk, the reliabilities increased from 53 to $65 \%$ to 81 to $85 \%$ with genotypes. The reliabilities decreased with parity for milk because of fewer phenotypes and lower heritability in later parities. On the other hand, the reliability for

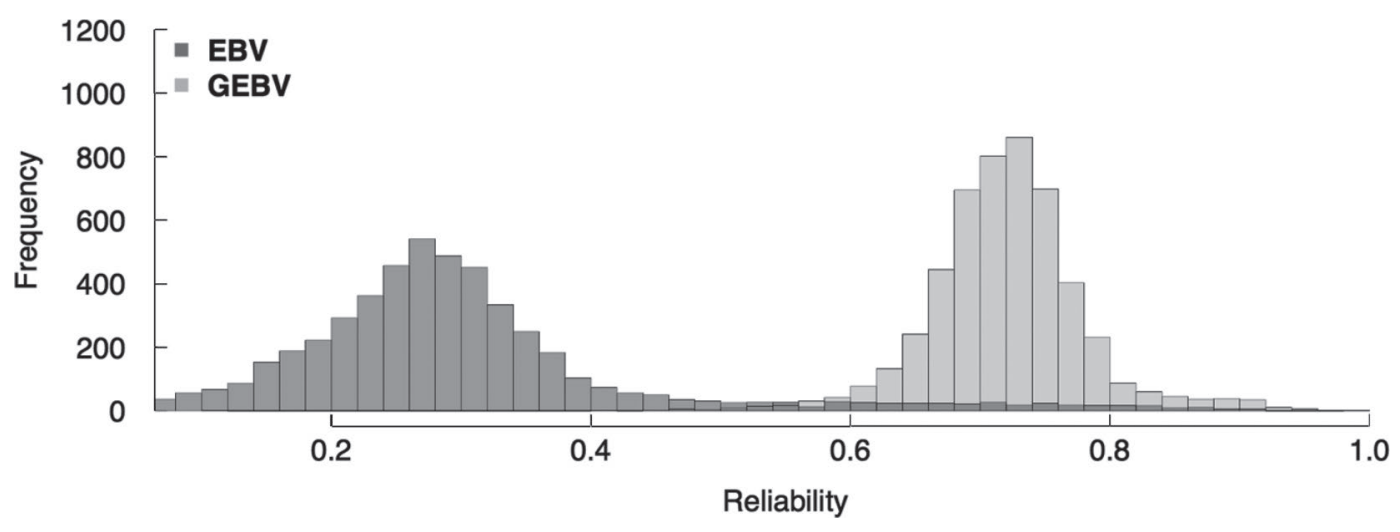

Figure 1. Distribution of reliability in EBV and genomic EBV (GEBV) for cow mortality in the first parity for 5,024 genotyped bulls. 


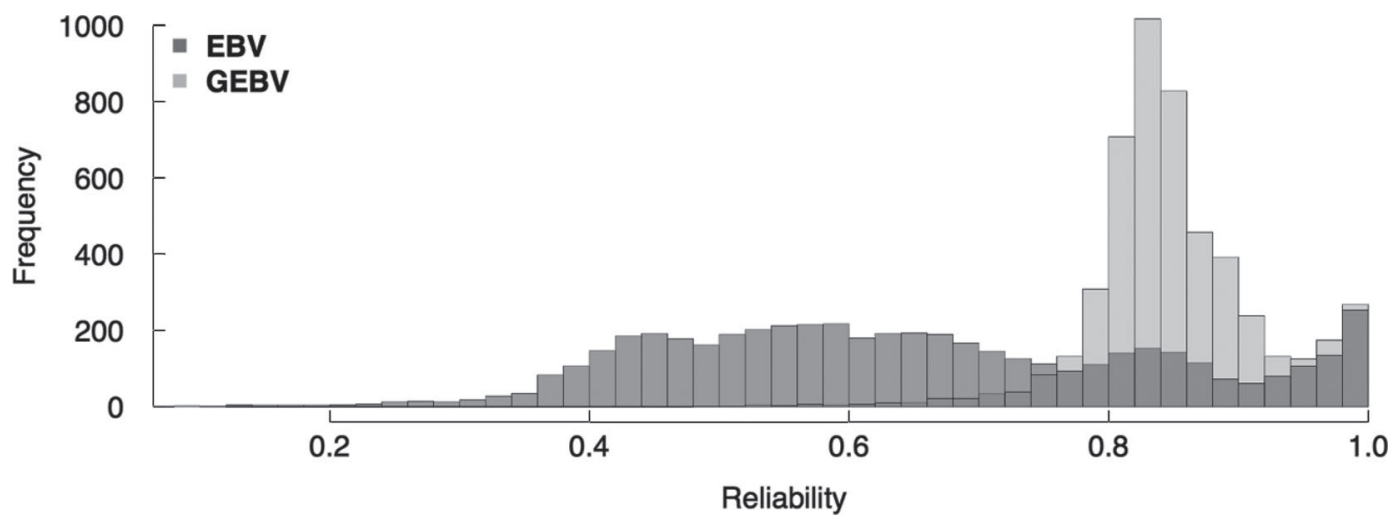

Figure 2. Distribution of reliability in EBV and genomic EBV (GEBV) for 305-d milk yield in the first parity for 5,024 genotyped bulls.

Table 6. Correlations between reliabilities estimated with direct inversion of MME and with Gibbs sampling in EBV and genomic EBV (GEBV) for cow mortality and 305-d milk yield in the first 3 parities for (all = 34,481 ) genotyped bulls

\begin{tabular}{|c|c|c|c|c|c|c|c|}
\hline \multirow[b]{3}{*}{ Parity } & \multirow{3}{*}{$\begin{array}{l}\text { No. of } \\
\text { genotyped } \\
\text { bulls }\end{array}$} & \multicolumn{4}{|c|}{ Cow mortality } & \multirow{2}{*}{\multicolumn{2}{|c|}{$\frac{305-\mathrm{d} \text { milk yield }}{\text { Linear model }}$}} \\
\hline & & \multicolumn{2}{|c|}{ Threshold model } & \multicolumn{2}{|c|}{ Linear model } & & \\
\hline & & EBV & GEBV & EBV & GEBV & EBV & GEBV \\
\hline 1 & 5,024 & 0.72 & 0.67 & 0.98 & 0.97 & 0.99 & 0.99 \\
\hline 2 & 4,528 & 0.74 & 0.69 & 0.98 & 0.96 & 0.99 & 0.99 \\
\hline 3 & 3,956 & 0.79 & 0.71 & 0.97 & 0.95 & 0.99 & 0.98 \\
\hline
\end{tabular}
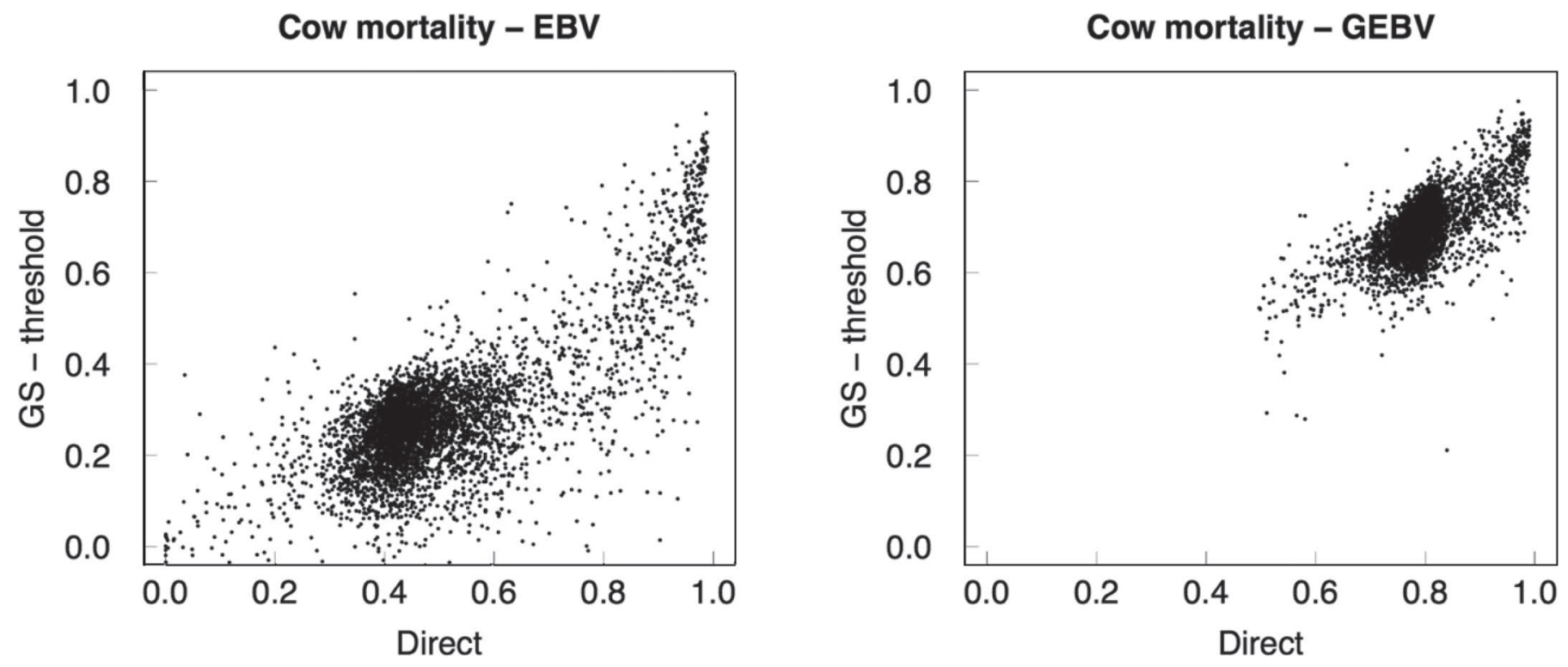

Figure 3. Scatter plots of reliability of EBV for 5,024 genotyped bulls and genomic EBV (GEBV) for 34,481 genotyped bulls calculated with direct inversion of the left-hand side of mixed model equations (direct) and with Gibbs sampling (GS) using a threshold model (GS - threshold) for cow mortality in the first parity. 

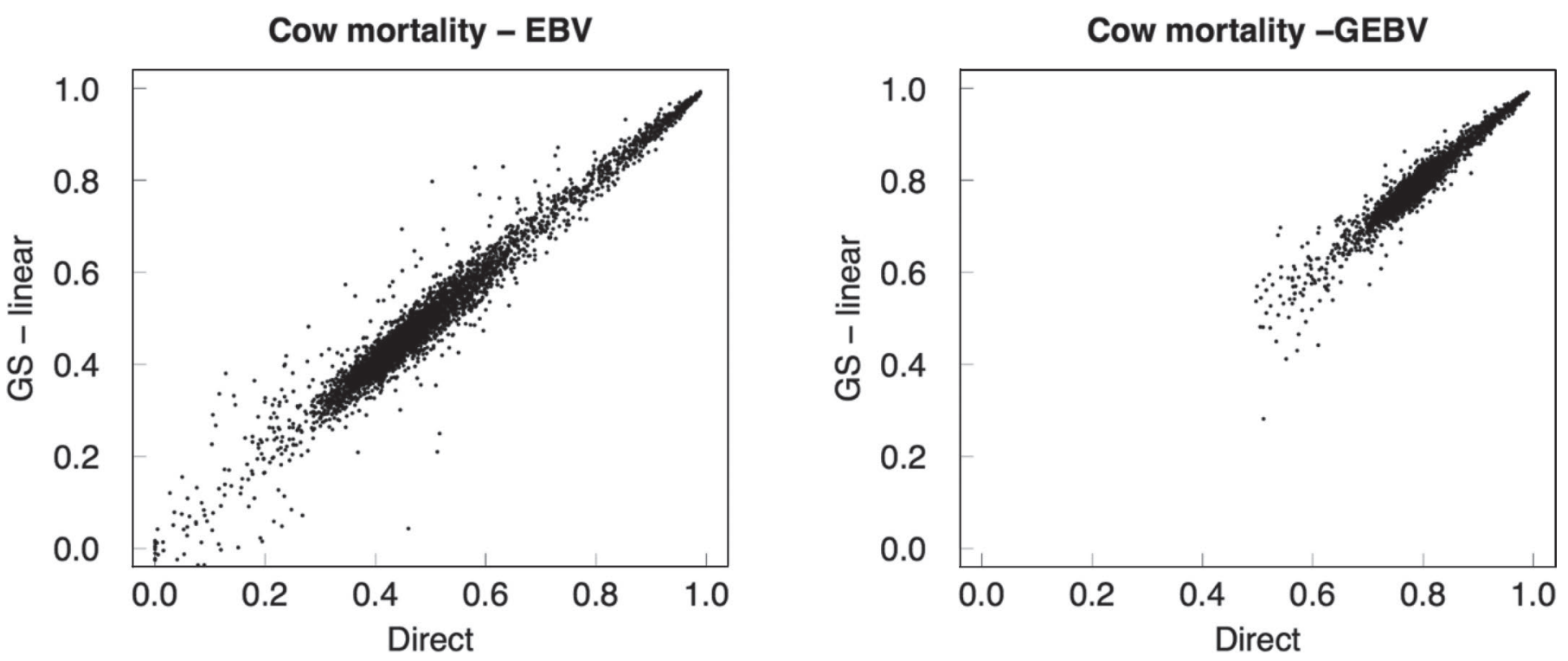

Figure 4. Scatter plots of reliability of EBV for 5,024 genotyped bulls and genomic EBV (GEBV) for 34,481 genotyped bulls calculated with direct inversion of the left-hand side of mixed model equations (direct) and with Gibbs sampling (GS) using a linear model (GS - linear) for cow mortality in the first parity.

mortality was approximately constant because reduction in phenotypic information was compensated by higher incidences and slightly higher heritability in later parities. For all genotyped bulls, the reliabilities were 1 to $2 \%$ higher for cow mortality and 4 to $6 \%$ lower for milk than those for the common genotyped bulls with daughters. These reliabilities were calculated from posterior standard deviations of Gibbs samples using the threshold model for mortality and with the linear model for milk. The reliability for cow mortality was also calculated with the linear model as shown in Table 5. The reliabilities were 15 to $20 \%$ in EBV and 7 to $8 \%$ in GEBV higher than those calculated with the threshold model. The official reliability in GEBV for milk is 78\% (Council on Dairy Cattle Breeding, 2016b). Wright and VanRaden (2016) obtained reliabilities for
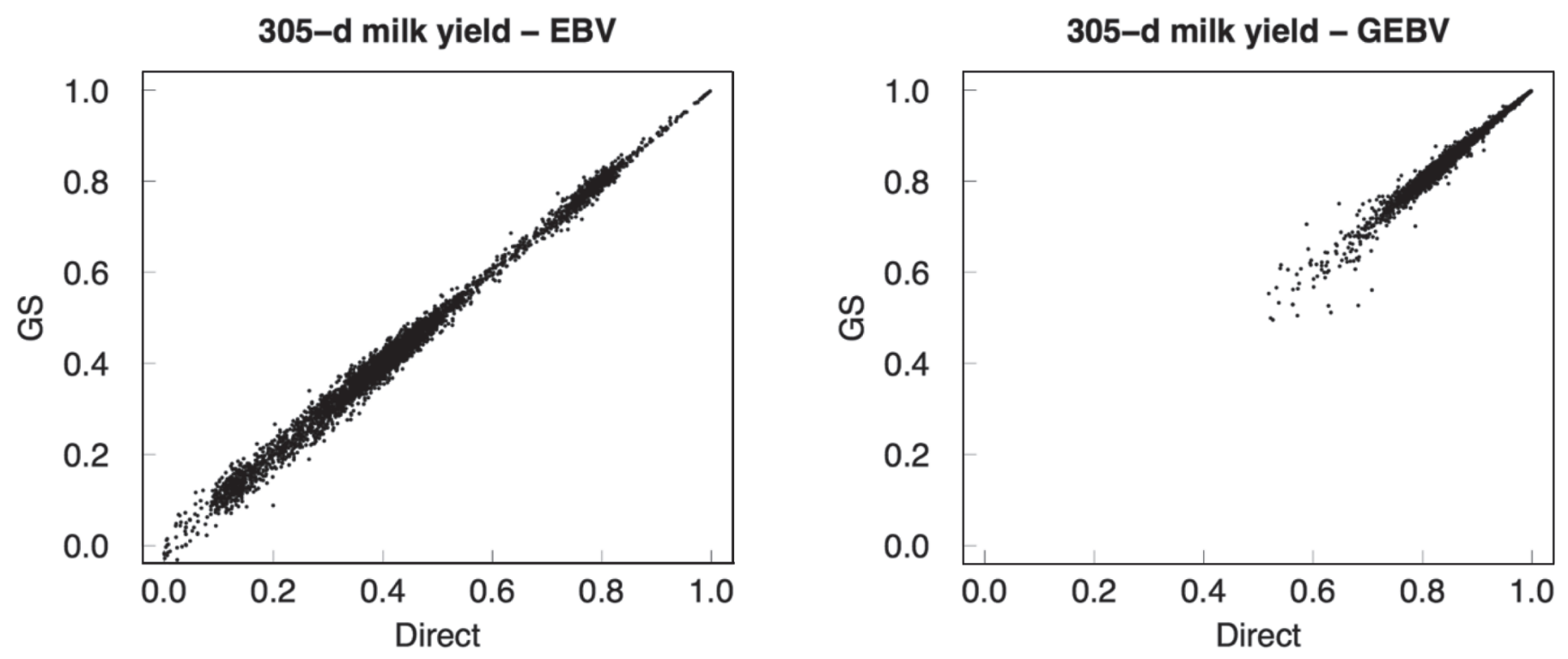

Figure 5. Scatter plots of reliability of EBV for 5,024 genotyped bulls and genomic EBV (GEBV) for 34,481 genotyped bulls calculated with direct inversion of the left-hand side of mixed model equations (direct) and with Gibbs sampling (GS) for 305-d milk yield in the first parity. 
Table 7. Correlations of SNP marker effects between cow mortality and 305-d milk yield in the first 3 parities (number of SNP in parentheses)

\begin{tabular}{lrrrrrr}
\hline & \multicolumn{9}{c}{ Parity } \\
\cline { 2 - 7 } $\mathrm{x}=\mid$ SNP marker effect $\mid$ & \multicolumn{3}{c}{1} & \multicolumn{2}{c}{2} & \\
\hline All & 0.64 & $(36,951)$ & 0.64 & $(36,951)$ & 0.42 & $(36,951)$ \\
$\mathrm{x}<1.0^{1}$ & 0.32 & $(20,789)$ & 0.31 & $(20,558)$ & 0.18 & $(19,350)$ \\
$1.0<\mathrm{x}<2.0$ & 0.63 & $(13,320)$ & 0.63 & $(13,520)$ & 0.38 & $(14,359)$ \\
$2.0<\mathrm{x}<3.0$ & 0.78 & $(2,544)$ & 0.79 & $(2,576)$ & 0.57 & $(2,936)$ \\
\multicolumn{1}{c}{$3.0<\mathrm{x}<4.0$} & 0.83 & $(278)$ & 0.83 & $(271)$ & 0.62 & $(284)$ \\
$4.0<\mathrm{x}$ & 0.89 & $(20)$ & 0.86 & $(26)$ & 0.73 & $(22)$ \\
\hline
\end{tabular}

${ }^{1}$ Standardized SNP marker effects.

livability of $30 \%$ for nongenomic and $56 \%$ for genomic predictions. The difference in reliabilities could be due to different data sets, models, and calculation methods.

Figures 1 and 2 show the distributions of reliabilities in EBV and GEBV of cow mortality and 305-d milk yields for 5024 genotyped bulls, respectively, corresponding to the average reliabilities calculated with linear models for the first parity, shown in Table 5 . Reliabilities in EBV were distributed widely between 1 and $99 \%$, whereas reliabilities in GEBV were more normally distributed with means close to the values in Table 5.

\section{Correlations of Reliabilities by Direct and MCMC Methods}

Table 6 shows correlations between reliabilities estimated with the direct inversion of the MME and with MCMC via Gibbs sampling in EBV and GEBV for the first 3 parities. The correlations for cow mortality using the threshold model were lower, compared with $>0.9$ for milk. However, using the linear model, the correlations for cow mortality were high $(>0.9)$. Figures 3, 4, and 5 support this result, showing highly correlated scatter plots of reliabilities for cow mortality when using the linear model. Using the threshold model generates PEV with the liability (nonlinear) scale from posterior means and standard deviations for EBV and GEBV assuming known genetic parameters. This does not match the reliability calculated by inverting the MME, which is a linear model.

\section{SNP Marker Correlations}

Genetic correlations between milk and cow mortality suggest pleiotropy, which can involve genes with small or large effects on multiple traits. Assuming that SNP marker effects are partially proxies for QTL effects, it is of interest whether the genetic correlation between the traits is mostly between SNP markers with small or large effects. Table 7 shows positive correlations of
SNP marker effects between cow mortality and 305-d milk yields in the first 3 parities. The correlations were calculated with standardized SNP marker effects on cow mortality and on 305-d milk yields, ranging from 0 to 1,1 to 2,2 to 3,3 to 4 , and 4 . The correlations for mortality and milk with $>3$ standard deviations were $>0.8$ in the first 2 parities and $>0.7$ in the third parity. The correlations were lower with smaller standard deviations. Higher correlations for fewer SNP markers suggest that pleiotropy can occur in only a few genes. On the other hand, lower correlations for more SNP markers could be due to a large number of small SNP effects with large sampling errors. Low correlations in later parities may be due to highly selected cows for milk production or disease resistance. High-producing cows with metabolic, physiological, or immunological

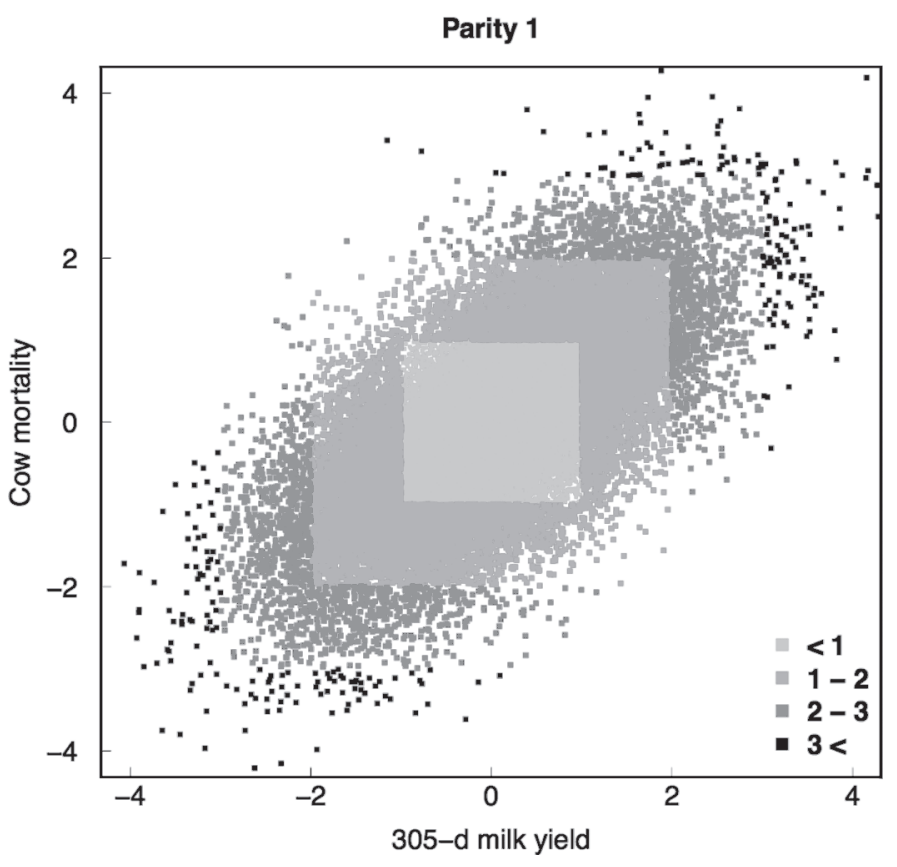

Figure 6. Standardized SNP marker effects of cow mortality and 305-d milk yield in the first parity for genotyped bulls. 
problems would have already been dead in the early parity. Miller et al. (2008) reported that frequency of deaths increased with age and was higher in the early stage of lactation, and Dechow and Goodling (2008) also reported higher mortality in the early stage of lactation while a cow produces more milk. Alvåsen et al. (2012) showed that in Sweden, higher mortality is associated with larger herd size and lower mortality was observed in higher herd average milk yields. The corresponding scatter plot to Table 7 is shown in Figure 6. Darker plots represent larger SNP effects for both mortality and milk in the first parity, demonstrating a positive relationship between cow mortality and milk production.

\section{SNP Marker Variances}

Figure 7 presents Manhattan plots created from SNP variances explained by windows of 30 adjacent SNP for mortality, and Figure 8 presents the same plots for 305-d milk yields. For both traits, nearly all windows explained less than $0.6 \%$ variance. The exceptions were peaks that reached $4 \%$ for milk and $2.5 \%$ for mortality and that occurred around the location of the DGAT1 gene on BTA 14. Large effects for production traits have been found for DGAT1 in the past (Grisart et al., 2002; Ashwell et al., 2004; Schnabel et al., 2005; Cole et al., 2009). No studies in dairy had looked at the effect of DGAT1 on mortality. Berry et al. (2010) reported no effect of $D G A T 1$ on longevity, which is partially related to mortality. In a mice study, overexpression of DGAT1 under certain conditions reduced mortality (Liu et al., 2009). The result in this study suggests that DGAT1 on BTA 14 could be associated with cow mortality as well as milk production.

\section{Genetic Selection for Cow Mortality}

Figures 9 and 10 show genetic trends of cow mortality and 305-d milk yield in the first parity calculated

Parity 1

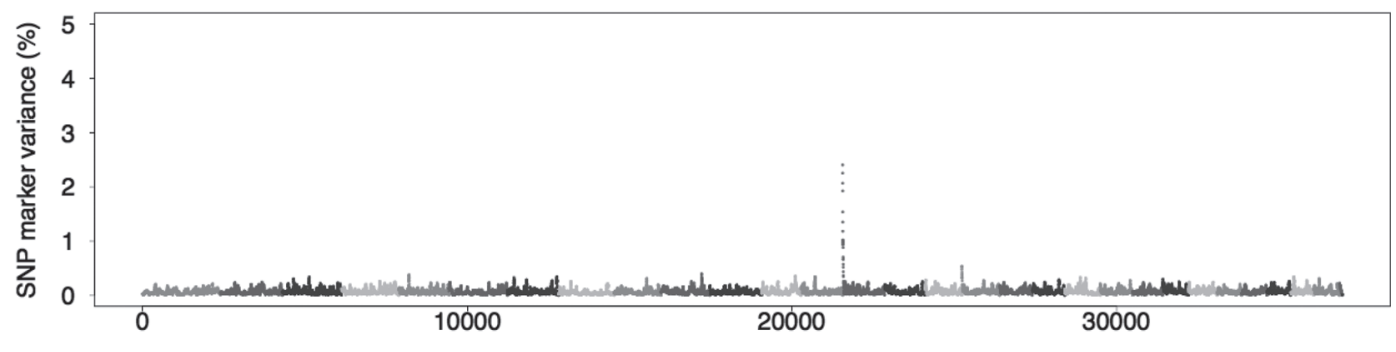

Parity 2

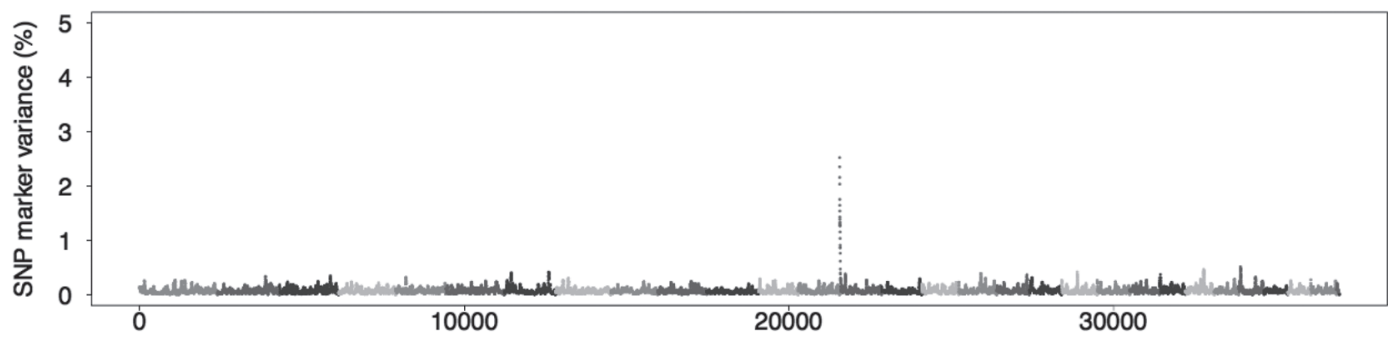

Parity 3

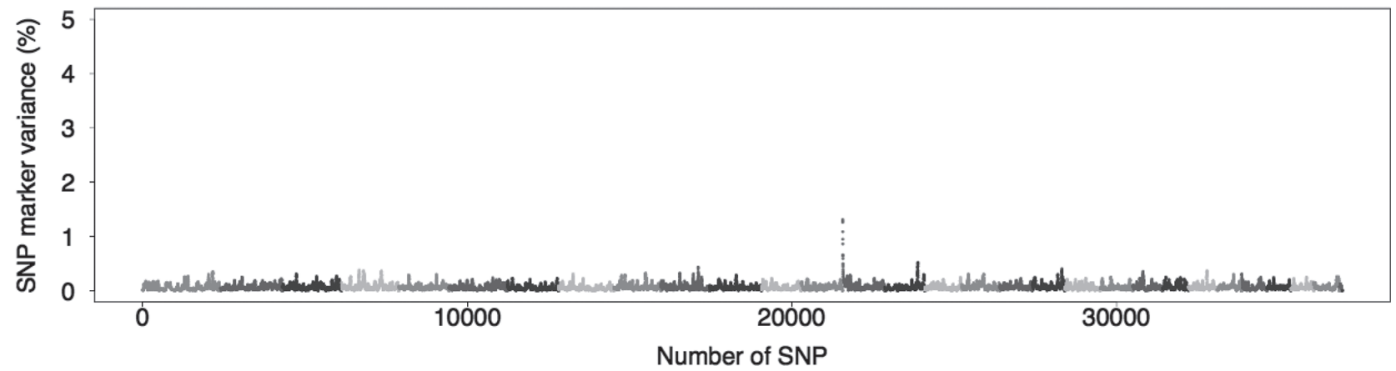

Figure 7. SNP marker variances for cow mortality in 3 parities. 
Parity 1

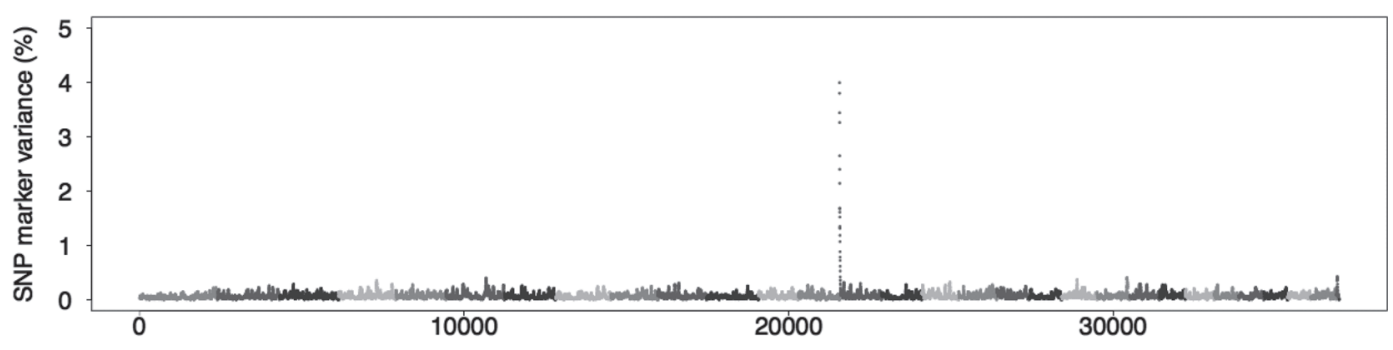

Parity 2

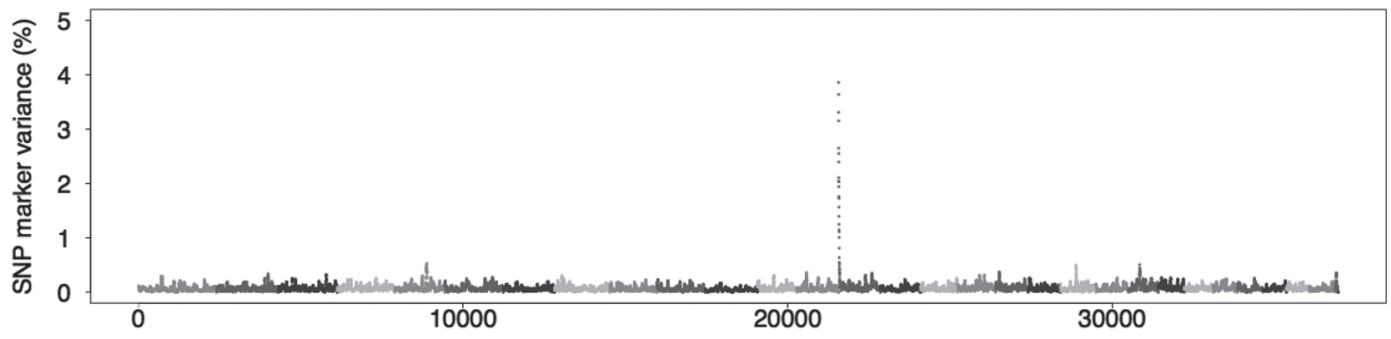

Parity 3

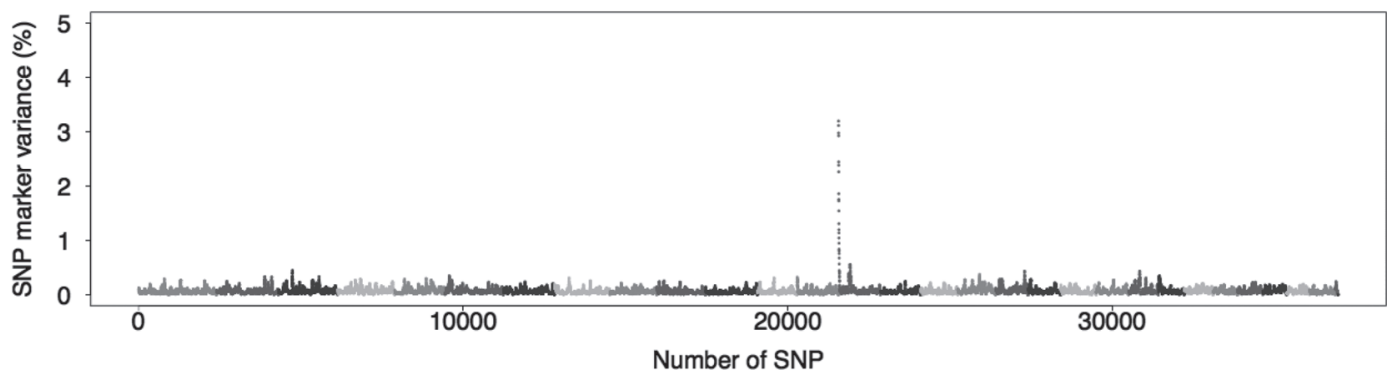

Figure 8. SNP marker variances for 305-d milk yields in 3 parities.

using GEBV for all cows with records, all bulls, and only genotyped bulls. The base was set to the average GEBV for cows with records born in 1995. The genetic trend of cow mortality for all cows increased from 1995

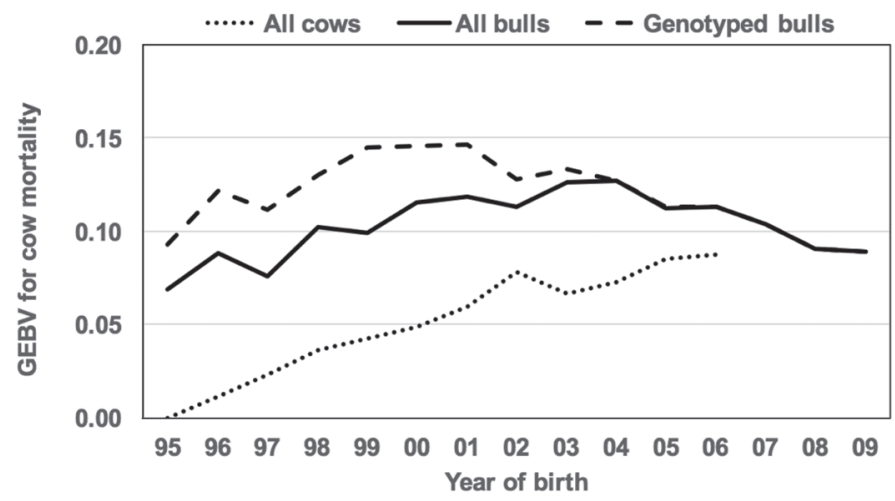

Figure 9. Genetic trends estimated with genomic EBV (GEBV) of cow mortality for all cows, all bulls, and genotyped bulls. to 2006, whereas that for all bulls decreased after 2003. The trend for only genotyped bulls started declining in 2000. The genetic trend of milk production for cows

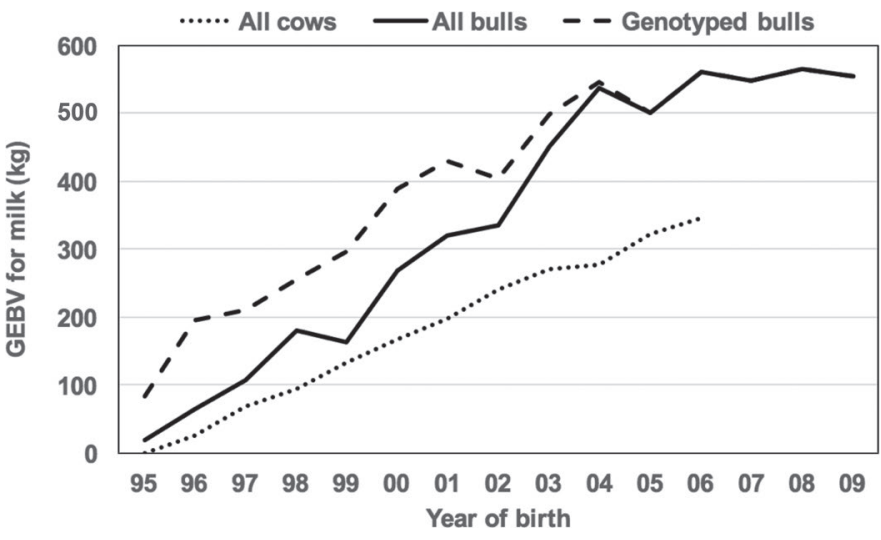

Figure 10. Genetic trends estimated with genomic EBV (GEBV) of 305-d milk yield for all cows, all bulls, and genotyped bulls.

Journal of Dairy Science Vol. 100 No. 9, 2017 
steadily increased, whereas the increase for bulls were small for the last $5 \mathrm{yr}$. The trend for genotyped bulls were always higher than that for all bulls from 1995 to 2003, indicating that those genotyped bulls were highly selected. Higher GEBV of cow mortality for genotyped bulls might have responded to this trend. VanRaden (2016) found declining trends for livability in US Holsteins until 2000 for sires and 2003 for cows. Then, the trends became positive, which they attribute to selection for productive life. Genetic selection for a major trait could create correlated responses. With long-term selection for production (quantitative) traits, genetic correlations with unselected traits eventually become negative (Falconer, 1989). The decline in unselected traits may be very slow for traits with low heritability. For example, a negative response to the secondary trait was experienced during long-term selection in broiler chickens, where several breeding companies experienced similar problems despite separate selection by each company (Hill, 2016). Lande and Thompson (1990) stated that segregating genes of major effects usually have deleterious pleiotropic effects. This could be due to the fact that after long-term selection, genes of large effects become fixed unless pleiotropy prevents them from fixing. Pleiotropy of a major gene for milk and mortality may lead to undesirable effects of selection for highly heritable traits. Undesirable effects of selection on secondary traits could be overcome with direct selection on those traits.

\section{Implementation of Genomic Evaluation}

The results from this study need to be treated with caution because of data editing issues and modeling limitations. The available data were reports from DHI dairy producers. Each producer can report "death" subjectively when the cause of death is multiple. Because determining whether termination was due to mortality is complex, the study required careful editing (Tsuruta et al., 2015). In this study, all results were produced by parity. It would be preferable to analyze milk for all parities together, either with a repeatability or a multiple trait model. However, mortality is a censored survival trait, and joint modeling of survival and regular traits may not be straightforward.

Analyzing mortality with threshold models allows for easy accommodation of regions/farms with increasing mortality. In such a case, parameters for mortality need not be re-estimated, and predictions of mortality can easily be made region specific. The predictions can be adjusted not only for each herd but also for future cases, assuming that a threshold to mortality changes. The predictions can be transformed to the probability scale by adjusting for any circumstances when they are calculated on the liability scale.

\section{CONCLUSIONS}

A threshold-linear model of cow mortality and milk yields is applicable to analyzing large data sets. It allows for the inclusion of genomic data and calculation of reliability for validation with Gibbs sampling. The increase in reliability with genomic information is particularly high for cow mortality. The analysis of SNP marker effects and common regions of the genome for cow mortality and 305-d milk yields indicates potential pleiotropy or gene interactions close to DGAT1.

\section{ACKNOWLEDGMENTS}

This study was partially funded by the Holstein Association USA Inc. The authors thank USDA-Agricultural Research Service (Beltsville, MD) for providing DHI and genomic data.

\section{REFERENCES}

Aguilar, I., I. Misztal, D. L. Johnson, A. Legarra, and H. Wang. 2014. PREGSF90 - POSTGSF90: Computational tools for the implementation of single-step genomic selection and genomewide association with ungenotyped individuals in BLUPF90 programs. Abstract 680 in Proc. 10th World Congr. Genet. Appl. Livest. Prod., Vancouver, Canada. https://asas.org/docs/defaultsource/wcgalp-posters/680_paper_9756_manuscript_1666_0. pdf?sfvrsn $=2$.

Aguilar, I., I. Misztal, S. Tsuruta, A. Legarra, S. Tsuruta, and T. J. Lawlor. 2010. Hot topic: A unified approach to utilize phenotypic, full pedigree, and genomic information for genetic evaluation of Holstein final score. J. Dairy Sci. 93:743-752.

Alvåsen, K., M. Jansson Mörk, C. Hallén Sandgren, P. T. Thomsen, and U. Emanuelson. 2012. Herd-level risk factors associated with cow mortality in Swedish dairy herds. J. Dairy Sci. 95:4352-4362.

Ashwell, M. S., D. W. Heyen, T. S. Sonstegard, C. P. Van Tassell, Y. Da, P. M. VanRaden, M. Ron, J. I. Weller, and H. A. Lewin. 2004. Detection of quantitative trait loci affecting milk production, health, and reproductive traits in Holstein cattle. J. Dairy Sci. 87:468-475.

Berry, D. P., D. Howard, P. O'Boyle, S. Waters, J. F. Kearney, and M. McCabe. 2010. Associations between the K232A polymorphism in the diacylglycerol-O-transferase 1 (DGAT1) gene and performance in Irish Holstein-Friesian dairy cattle. Ir. J. Agric. Food Res. 49:1-9.

Cole, J. B., P. M. VanRaden, J. R. O'Connell, C. P. Van Tassell, T. S. Sonstegard, R. D. Schnabel, J. F. Taylor, and G. R. Wiggans. 2009. Distribution and location of genetic effects for dairy traits. J. Dairy Sci. 92:2931-2946.

Council on Dairy Cattle Breeding. 2016a. Changes to evaluation system (August 2016): Cow livability evaluation. Accessed Mar. 10, 2017. https://www.uscdcb.com/reference/changes/eval1608.htm.

Council on Dairy Cattle Breeding. 2016b. Comparison of December 2016 genomic and traditional evaluations. Accessed Mar. 10, 2017. https://www.uscdcb.com/eval/summary/comparexml_menu.cfm.

De Vries, A. 2013. Cow longevity economics: The cost benefit of keeping the cow in the herd. Pages 22-52 in Cow Longevity Conference Proceedings. August 28 to 29, 2013, Hanra Farm, Tumba, Sweden. DeLaval International AB, Tumba, Sweden. 
Dechow, C. D., and R. C. Goodling. 2008. Mortality, culling by sixty days in milk, and production profiles in high- and low-survival Pennsylvania herds. J. Dairy Sci. 91:4630-4639.

Falconer, D. S. 1989. Introduction to Quantitative Genetics, 3rd ed. John Wiley, New York, NY.

Gianola, D., and J. L. Foulley. 1983. Sire evaluation for ordered categorical data with a threshold model. Genet. Sel. Evol. 15:201-224.

Grisart, B., W. Coppieters, F. Farnir, L. Karim, C. Ford, P. Berzi, N. Cambisano, M. Mni, S. Reid, P. Simon, R. Spelman, M. Georges, and R. Snell. 2002. Positional candidate cloning of a QTL in dairy cattle: Identification of a missense mutation in the bovine DGAT1 gene with major effect on milk yield and composition. Genome Res. 12:222-231.

Hill, W. G. 2016. Is continued genetic improvement of livestock sustainable? Genetics 202:877-881.

Jamrozik, J., L. R. Schaeffer, and G. B. Jansen. 2000. Approximate accuracies of prediction from random regression models. Livest. Prod. Sci. 66:85-92.

Lande, R., and R. Thompson. 1990. Efficiency of marker assisted selection in the improvement of quantitative traits. Genetics 124:743756

Liu, L., X. Shi, K. G. Bharadwaj, S. Ikeda, H. Yamashita, H. Yagyu, J. E. Schaeffer, Y. H. Yu, and I. J. Goldberg. 2009. DGAT1 expression increases heart triglyceride content but ameliorates lipotoxicity. J. Biol. Chem. 284:36312-36323. https://doi.org/10.1074/jbc. M109.049817.

Lourenco, D. A. L., S. Tsuruta, B. O. Fragomeni, Y. Masuda, I. Aguilar, A. Legarra, J. K. Bertrand, T. S. Amen, L. Wang, D. W. Moser, and I. Misztal. 2015. Genetic evaluation using single-step genomic best linear unbiased predictor in American Angus. J. Anim. Sci. 93:2653-2662.

McConnel, C. S., J. E. Lombard, B. A. Wagner, and F. B. Garry. 2008. Evaluation of factors associated with increased dairy cow mortality on United States dairy operations. J. Dairy Sci. 91:1423-1432.

Miller, R. H., M. T. Kuhn, H. D. Norman, and J. R. Wright. 2008. Death losses for lactating cows in herds enrolled in dairy herd improvement test plans. J. Dairy Sci. 91:3710-3715.

Misztal, I., S. Tsuruta, D. A. L. Lourenco, Y. Masuda, I. Aguilar, A Legarra, and Z. Vitezica. 2016. BLUPf90 manual. Pages 35-36 in Quality control for G. Accessed May 5, 2017. http://nce.ads.uga. edu/wiki/doku.php?id=readme.pregsf90.

Ramirez-Valverde, R., I. Misztal, and J. K. Bertrand. 2001. Comparison of threshold vs linear and animal vs sire models for predicting direct and maternal genetic effects on calving difficulty in beef cattle. J. Anim. Sci. 79:333-338.

Rushen, J., and A. M. de Passillé. 2013. The importance of improving cow longevity. Pages 3-21 in Cow Longevity Conference Proceedings. August 28 to 29, 2013, Hanra Farm, Tumba, Sweden. DeLaval International AB, Tumba, Sweden.

Schnabel, R. D., T. S. Sonstegard, J. F. Taylor, and M. S. Ashwell. 2005. Whole-genome scan to detect QTL for milk production, con- formation, fertility and functional traits in 2 US Holstein families. Anim. Genet. 36:408-416.

Sorensen, D., and D. Gianola. 2002. Likelihood, Bayesian and MCMC Methods in Quantitative Genetics, Springer-Verlag, New York, NY.

Tokuhisa, K., S. Tsuruta, A. De Vries, J. K. Bertrand, and I. Misztal. 2014. Estimation of regional genetic parameters for mortality and 305-d milk yield of US Holsteins in the first 3 parities. J. Dairy Sci. 97:4497-4502.

Tsuruta, S., D. A. L. Lourenco, I. Misztal, and T. J. Lawlor. 2015. Genotype by environment interactions on culling rates and 305d milk yield of Holstein cows in three US regions. J. Dairy Sci. 98:5796-5805.

Tsuruta, S., and I. Misztal. 2006. THRGIBBS1F90 for estimation of variance components with threshold-linear models. Commun. 27-31 in Proc. 8th World Congr. Genet. Appl. Livest. Prod., Belo Horizonte, Brazil. Instituto Prociencia, Belo Horizonte, Brazil.

Tsuruta, S., I. Misztal, I. Aguilar, and T. J. Lawlor. 2014. Genome wide association study on cow mortality in three US regions. Proceedings, 10th World Congress of Genetics Applied to Livestock Production. Vancouver, Canada.

USDA-APHIS. 2008. Dairy 2007, Part II: Changes in the U.S. Dairy Cattle Industry, 1991-2007. USDA-APHIS-VS, CEAH. Fort Collins, CO, \#N480.0308.

Van Tassell, C. P., L. D. Van Vleck, and K. E. Gregory. 1998. Bayesian analysis of twinning and ovulation rates using a multiple-trait threshold model and Gibbs sampling. J. Anim. Sci. 76:2048-2061.

Van Vleck, L. D. 1993. Variance of prediction error with mixed model equations when relationships are ignored. Theor. Appl. Genet. 85:545-549.

VanRaden, P. 2016. Value of selecting for cow and calf livability. Interbull Ann. Meet., Puerto Varas, Chile, Oct. 25, 2016. Accessed Dec. 9, 2016. http://aipl.arsusda.gov/publish/presentations/MISC16/ Interbull2016_vanraden.pptx.

Varona, L., I. Misztal, and J. K. Bertrand. 1999. Threshold-linear versus linear-linear analysis of birth weight and calving ease using an animal model: II. Comparison of models. J. Anim. Sci. 77:2003-2007.

Wang, H., I. Misztal, I. Aguilar, A. Legarra, and W. M. Muir. 2012. Genome-wide association mapping including phenotypes from relatives without genotypes. Genet. Res. 94:73-83.

Wright, J. R., and P. M. VanRaden. 2016. Genetic evaluation of dairy cow livability. J. Dairy Sci. 99(E-Suppl. 1)/J. Anim. Sci. 94(ESuppl. 5):174 (Abstr. 0368).

Zhang, Z., J. Liu, X. Ding, P. Bijma, D. J. de Koning, and Q. Zhang. 2010. Best linear unbiased prediction of genomic breeding values using a trait-specific marker- derived relationship matrix. PLoS One 5:e12648. 